\title{
Development of a user-centered module: A contribution to flood-sustainable spatial planning
}

This article addresses user-related issues in flood-sustainable spatial planning. It presents the concept and methodological development of a user-centred module, one of three modules of a model for an integral system of flood-sustainable planning. By introducing daily routine analysis of a selected user profile, backgrounded by behaviour mapping, it addresses small but important data in the context of what is usually big-data analysis of flood modelling in order to bring the dynamics of everyday life into flood-sustainable planning. This user-centred mod- ule was developed and tested in the Planina Karst Field, a typical overflow karst field that is frequently flooded. It is a novel approach to addressing people's lives and their interactions with space that opens new perspectives on flood-related issues and can act as an alternative or complement to spatial-planning measures and processes.

Keywords: integrated modelling, user-centred approach, spatial planning, floods, behaviour mapping 


\section{Introduction}

This article is part of the ongoing basic research project Integral System of Flood-Sustainable Spatial Planning, co-financed by the Slovenian Research Agency. The aim of the project is to set up a conceptual model that simultaneously considers the influences of human habitation and water dynamics. Accordingly, this model has three interrelated modules: a hydrogeological module, an urban planning module, and a user-centred module. The hydrogeological module addresses the characteristics of daily water level and discharge values, as well as detailed spatial and temporal monitoring of water levels, model settings to test the validity of parameters suspected to influence flooding, and application of the results to a real case of a flood of a certain intensity. The user-centred module addresses individuals' engagement with areas affected by flooding via analysis of peoples' daily routines in flood and non-flood situations as well as their attitudes toward flooding where they live in terms of safety and quality of life, testing and considering the validity of qualitative data gathered through analysis of daily routines in relation to parameters suspected to influence flooding, and the possibility of an application of these findings to a real flood situation. Finally, the urban planning module addresses the potential of both modules in relation to existing planning practice, taking into account legislation, planning processes, and outcomes.

In this context, the project's hypothesis follows three interrelated components: 1) residency is the main activity in a place, 2) modelling is a practical and useful approach for flood prediction and warning, and 3) it is crucial to equally consider natural characteristics and human interventions in the environment.

The idea of integration as a multidimensional concept in research and planning is not new. Integrated assessments and modelling are found as analytical approaches in research and concepts of scenario building in planning processes, especially when examining the impacts and causes of environmental problems, including floods (e.g., Medema et al., 2008; Hering \& Ingold, 2012). Moreover, in recent decades several concepts, such as sustainable development (UN, 2015), the ecosystem approach (UNEP/CBD, 2000), and ecosystem services (MEA, 2005) - and more recently the nature-based solutions concept (UNEP, 2010; IUCN, 2012; Cohen-Shacham et al., 2016) - were introduced to spatial planning and development to introduce integral concepts into planning processes, policymaking, or governance. This reflects the fact that there is broad consensus on the need for integration; however, there is less agreement on what integration really means and how it can be effectively introduced into modelling processes. According to Hamilton et al. (2015), integrated assessment and model- ling (IAM) is considered the integration of components across and within ten interrelated dimensions, which are arranged in three key sections: 1) key drivers of integration, 2) methodological aspects requiring integration, and 3) aspects of the system to be integrated. This last section is divided into four interrelated dimensions: 1) the human setting, 2) the natural setting, 3) spatial scales, and 4) temporal scales. They may directly underlie the content of the proposed conceptual model as well as the user-centred module. Accordingly, this article focuses on inclusion of the notion of dynamics of everyday life into the system of sustainable planning and flood modelling, and it refers to the conception of and methodological approach to the user-centred module.

\section{Background}

According to Hamilton et al. (2015), the human setting relates to all human elements relevant to a problem, and it may include population factors, politics, organizations, culture, technology, and economic sectors, or it may address human behaviour and choices mostly represented through agent-based modelling. This shows that several disciplines address human settings as a component in their fields of interests, regarding accuracy of the subject addressed and the scale (Golledge \& Stimson, 1997). However, water-resource management in flood protection is still not well grounded, especially at the micro level (e.g., Medema et al., 2008; Hering \& Ingold, 2012). For spatial planning, simulation of micro-level human activities that influence macro-level patterns is often presented through agent-based modelling (e.g., Jiang \& Xiaobai, 2010; Müller et al., 2013); this mostly relies on big-data surveys or bases.

However, human systems are relational and, as further stressed by Hamilton et al. (2015), they are dependent on goods and services provided by the natural system and at the same time they modify the processes and components of the natural system through their activities and resource use. Therefore, setting up a user-centred module within the conceptual model for an integral system of flood-sustainable planning should be considered and this should be related to the hydrogeological (natural system) and urban planning module. According to Hamilton et al. (2015), this corresponds well with the aspect of the other two key sections: key drivers of integration and methodological aspects requiring integration.

Hamilton et al. (2015) define the natural setting as a dimension that relates to the integration of components of biophysical systems of interest (climate, land, water, atmospheric, and/ or ecological systems). However, they note that one output cannot be the input for the others (the rest of the process), but that it is crucial to consider that natural components may change in relevance by scale; for example, something at 
a small scale may be important for another dimension, which may have causes or impacts at a larger scale. This aspect must also be considered in spatial planning, especially in relation to flood-sustainable planning, because causes and effects may be manifested at very different locations and are greatly dependent on time and scale. Obviously, natural settings reflect uncertainty, complexity, and dynamics, and they are therefore characterized by ongoing changes. In relation to spatial planning, Nesshöver et al. (2017) call for adaptive management approaches, in which goals and actions are adapted to ongoing changes. In this respect, integration of socioeconomic and environmental considerations through integrated modelling is still rare in social studies (e.g., urban studies). However, it is becoming increasingly common for assessing and managing natural resources (e.g., Kragt et al., 2011; Laniak et al., 2013) and agricultural systems (e.g., van Ittersum et al., 2008). Integrated models simulating water flow usually involve various surface structures and levels (e.g., land surface, surface water, and groundwater flow systems), but do not address other primarily non-spatial / non-environmental characteristics (e.g., small and slow qualitative data on dynamic patterns of spatial use during daily activities).

The aspects of the human setting and natural setting directly reflect the notion of socio-ecological research, which addresses dynamic and coupled interactions between human and natural systems, emphasizing the coevolution of natural and social systems, in which understanding changes in one requires understanding changes in the other, rather than treating them separately (e.g., Young et al., 2006; Vespignani, 2012). This viewpoint is reflected in the development of the conceptual model for an integral system of flood-sustainable planning and represents a powerful base and determination for setting up a user-centred module as one of the model's components. To understand environmental problems and help design effective policies, it is essential to understand the underlying human drivers. Nesshöver et al. (2017) point out that there is a need to develop and gradually put into practice a sort of socio-ecological modelling, stressing among other things the importance of monitoring social changes and most of all starting to define them (from the planning perspective) with regard to the characteristics and context of a place. Developing the bipolar socio-ecological concept further, Rebernik et al. (in press) discuss a four-dimensional model of addressing social challenges, introducing a component at the relational level, focusing on the relations between users and the environment/government, users and technology, and the environment/government and technology.

Through enhancement of such concepts, local knowledge is introduced into planning and research, either via information such as what people know and what experience they have (a historical dimension), or from information on how they function and manage to achieve a sustainable or desirable way of life. In developing a user-centred module, two methods addressing spatial-use relationships were introduced: GIS behaviour mapping (e.g., Goličnik Marušić \& Marušić, 2012) and time quality assessment (TQA; Marušić \& Goličnik Marušić, 2016, 2017), both reflecting relations between users, the environment or governance, and technology. The first addresses the micro scale, analysing dynamic patterns in the use of selected places by time of day, time of week, user group or age group, type of activity, and cohabitation of activities among themselves, as well as the place configuration and activities. TQA is an advanced approach, constituted as an integrated modelling frame, analysing the daily routines of user profiles and assessing values of places via the quality of time spent in a place, including users' economic means to spend that time in a place.

TQA with the concepts of daily routines as components of the user-centred module may be paralleled by a time-scale dimension from Hamilton et al's (2015) integrated modelling approach. It is important to consider the characteristics of time scales addressing processes that, as shown by Hamilton et al. (2015), can occur over timeframes spanning minutes to hours or less (e.g., some biological or chemical functions), or days to weeks (e.g., ecological processes), whereas others may occur over years (e.g., socioeconomic processes), decades, or longer (e.g., species assemblage shift or climate change). The time dimension is especially relevant because natural and human settings operate in different timeframes. When building a model for an integral system of flood-sustainable planning and its constituent modules, the challenge is to recognize a phenomenon with a short timeframe as an input for the process of a longer timeframe, or vice versa. Time scales for natural or social processes always take place in a certain environment, and so they are related to a spatial scale; therefore, they are interconnected. In the research for this article, all four dimensions claimed to be essential aspects of system to be integrated (Hamilton et al., 2015) are conceptually reflected in the model and are interpreted within each of its modules (see Figure 1).

\section{Methodology for user-centred module design}

The module development followed a broader concept of user engagement in spatial development issues. However, it did not apply a concept of multilevel stakeholder involvement usually managed by top-down planning process protocols. It instead followed an often-overlooked qualitative bottom-up, slow, small, and deep-data-oriented research approach, based 


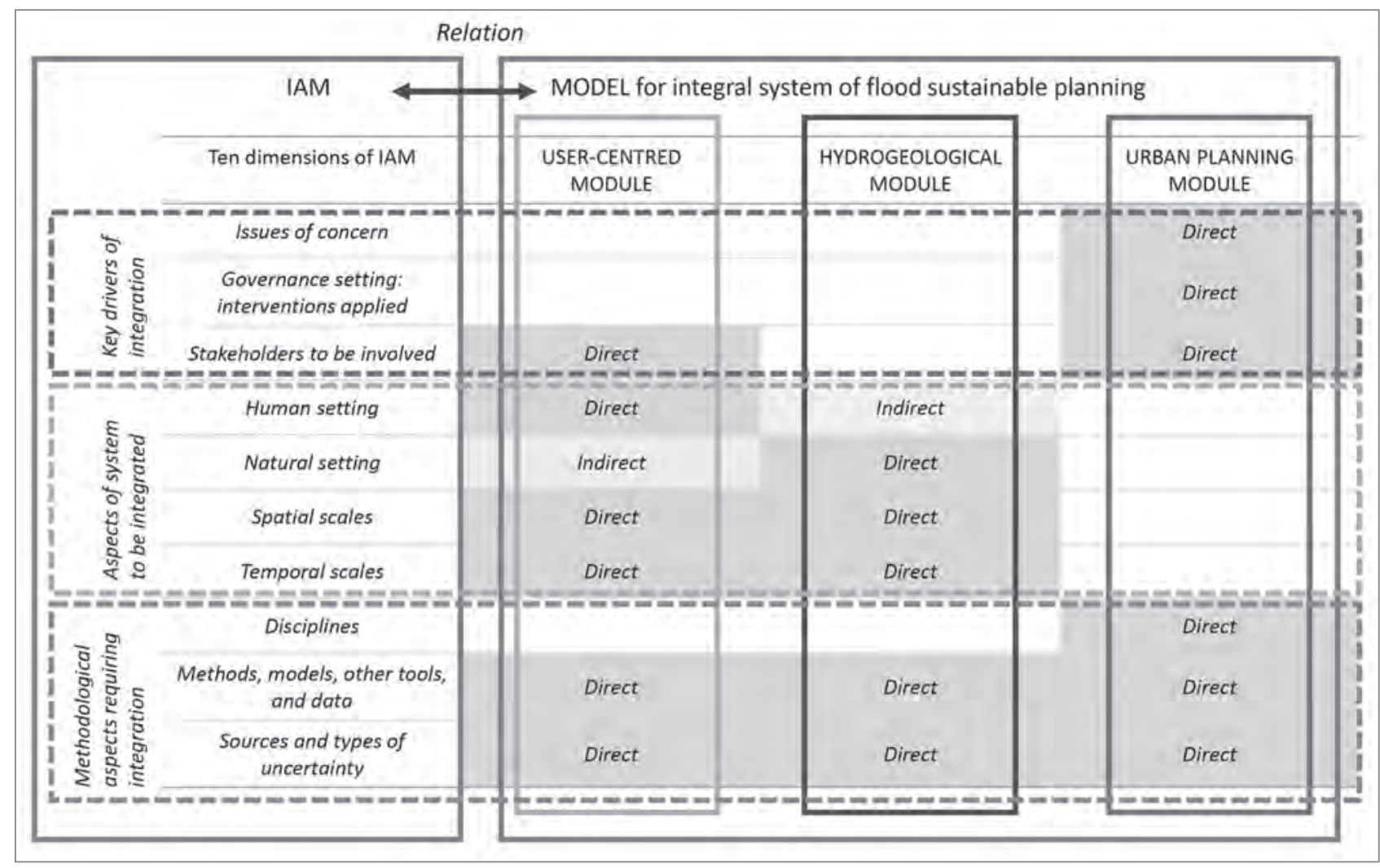

Figure 1: The conceptual relation between Hamilton et al's (2015) concept of IAM (left box) and the conceptual model for an integral system of flood-sustainable planning and its modules (right box; illustration: Barbara Goličnik Marušić).

on ethnographic research implementing components of user-oriented methods for studying spatial-use relationships: behaviour mapping and time quality assessment (TQA). Both methods resulted in the combined concept of a user-profile daily routine, which shows spatial-temporal dimensions of peoples' engagement with a place of interest. This concept of daily routines represents the main dynamics related to the social component of the model. However, in addition to analysis of peoples' daily routines in flood and non-flood situations, the model also addresses various other issues - from attitudes toward flooding, perceptions of safety and quality of life to typology and operability of data - and so a well-structured user-centred module design protocol was followed:

- Spatial setting;

- Defining relations between users, space, and flooding;

- Defining research techniques;

- Methodology;

- Data organization and coding;

- Analysing and interpreting the data collected;

- Valorization of the module as a spatial planning analysis and interpretation tool.

The protocol steps referring to preparatory activities for module design are commented on in Section 3, and the protocol steps for testing (implementation and valorization) of the module are commented on in Section 4. While designing the module, the following working hypothesis was formulated regarding the potential applied value of the module for spatial planning: Building and testing the module on or around a case where people are used to living with floods may result in greater applied value because regular floods force people to react; they may be more aware of threats and may be better skilled at adaptation. This may help shape the module toward effective (adaptation, management, and planning) solutions aimed at proactive solutions.

\subsection{Spatial setting}

The original research proposal selected an area where it was possible to develop a comprehensive approach to a flood-related place-sensitive and people-oriented conceptual model to help understand related dynamic processes and to promote integrated planning tools and practices. Accordingly, the Planina Karst Field in southwestern Slovenia was selected as the study area.

Hydrologically, the Planina Karst Field is an important confluence of karst water from several subcatchments. The total size of the catchment is estimated at $746 \mathrm{~km}^{2}$. In the southern part of the karst field, water emerges from Unica and Malenščica springs. Water is discharged diffusely from Malenščica Spring, and from Unica Spring water flows through a well-developed 
system of karst channels. The two watercourses join in the Unica River, which crosses the karst field and sinks on its northern and western edges. The water eventually re-emerges at the edge of the Ljubljana Basin as the Ljubljanica River. The Planina Karst Field has an area of over $10 \mathrm{~km}^{2}$ and has a relatively flat bottom with elevations between 442 and $447 \mathrm{~m}$. It is a typical example of an overflow karst field that is frequently flooded. On average, the karst field is flooded forty-one days per year. The flood (lake) level in the karst field varies by approximately eight metres, from 442 to $450.2 \mathrm{~m}$; the volume of water during a severe flood can reach approximately 26 million $\mathrm{m}^{3}$ with a lake area of $10 \mathrm{~km}^{2}$ (Kovačič \& Viršek Ravbar, 2010; Viršek Ravbar et al., 2012).

The hydrogeomorphological characteristics of the Planina Karst Field crucially contribute to variability of the landscape during the year. In terms of landscape variety, the characteristic patterns in the karst field include meanders of the Unica River, vegetation units, dominant individual trees, and agricultural land use (grassland), which together with natural characteristics of the area form a unique combination of cultural and natural landscapes (Marušič \& Jančič 1998). The fields and settlements are on a slightly raised narrow terrace above the flood plain. The karst field is a nature park, a recognized part of the cultural landscape and natural environment, with several levels of nature conservation status (Naravovarstveni atlas, 2018).

The largest and the oldest settlement is Planina. It is located on the elevated edge of the Planina Karst Field (the foothills of Mount Planina); this ribbon settlement has two nuclei. The majority of the population along the karst field, about 55\%, lives in Planina. The village of Laze, on the opposite side of the karst field, has $23 \%$, and $16 \%$ of the population lives in Grčarevec in a somewhat isolated arm of the northwest corner of the karst field. From 2008 to 2017, the population growth index was +104.8 for these villages.

When the Planina Karst Field is filled with water at a level of $447 \mathrm{~m}$, about $130 \mathrm{~m}$ of the lowest part of the road from Planina to Laze is underwater. This shows how water may affect people's lives in the area. At this point, houses and other buildings are not affected. When the water level reaches $449 \mathrm{~m}$, the entire road connecting Laze and Planina is flooded. The road from Planina to Hasberg Castle is also flooded. Travel between settlements is possible by taking bypass roads. Buildings are affected when the water level reaches $450 \mathrm{~m}$; this affects some that have been there for more than one hundred years (Figure 3). When the water level reaches $453 \mathrm{~m}$, the direct connection between Hasberg Castle and Laze via Planina (the hamlet of Dolnja Planina) is flooded, and buildings are also flooded (see Figure 4)

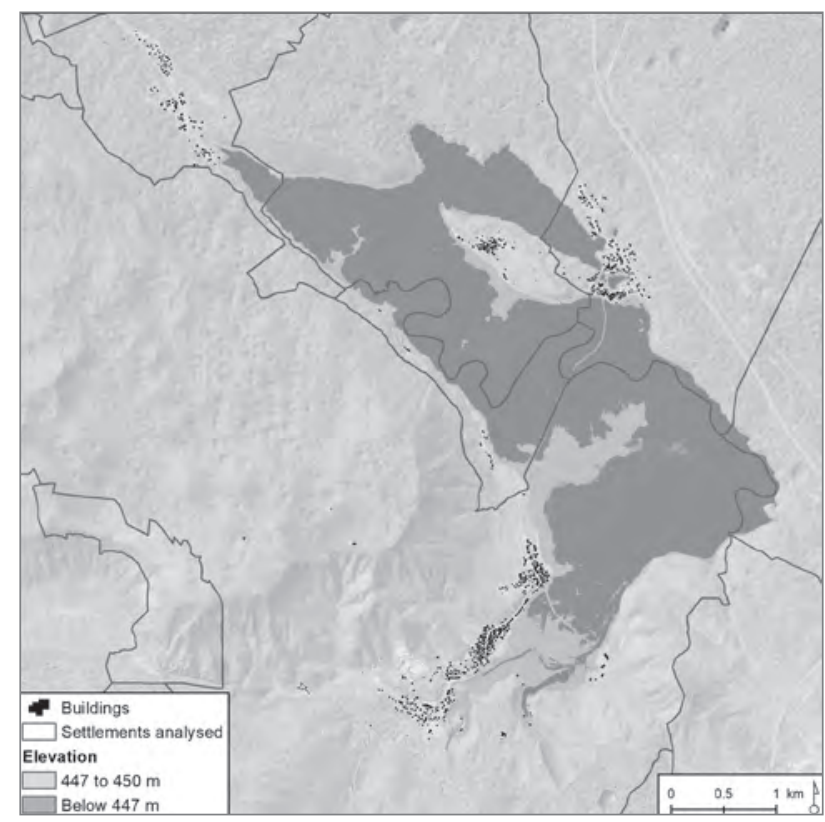

Figure 2: The Planina Karst Field with flood level marked (map by: Simon Koblar; source: Agencija Republike Slovenije za okolje, 2015 and Statistični urad Republike Slovenije, 2018a).

The STAGE bottom-up adjusted approach by the Slovenian Statistical Office (Statistični urad..., 2018b), which can help interpret big data in a small-data manner based on a grid data system, was used to better understand the study area and to prepare a data-gathering scale-frame for a user-centred module. This is conceptualized in a bottom-up manner and is oriented toward small data and its interpretation rather than big data, which do not fit the small-scale local context well. The village of Liplje has the sparsest population. The settlements of Laze, Jakovica, and Grčaravec have a similar population density, and Planina is the most densely populated settlement in the area, with a few locations where thirty to forty-two people live per $100 \times 100 \mathrm{~m}$ grid unit (see Figure 5).

\subsection{Defining relations between users, space, and flooding}

Content-wise, the main challenge in user-centred module development is the notion of user-space-flood relations. To introduce soft and qualitative dimensions of flood-related issues, one of the initial steps of module building sought to understand these relations. Several topics were relevant, such as living with flooding, threat and fear, interest in the landscape for its appearance and in nature as a process, being part of such a process, being influenced by floods, exacerbating the effects of flooding by living there, and so on. A series of brainstorming meetings resulted in identifying related issues and target issues. Four main target issues were identified: the usual daily routine in the karst field when there is no flooding, the usual daily routine in the karst field when it is flooded, threats 


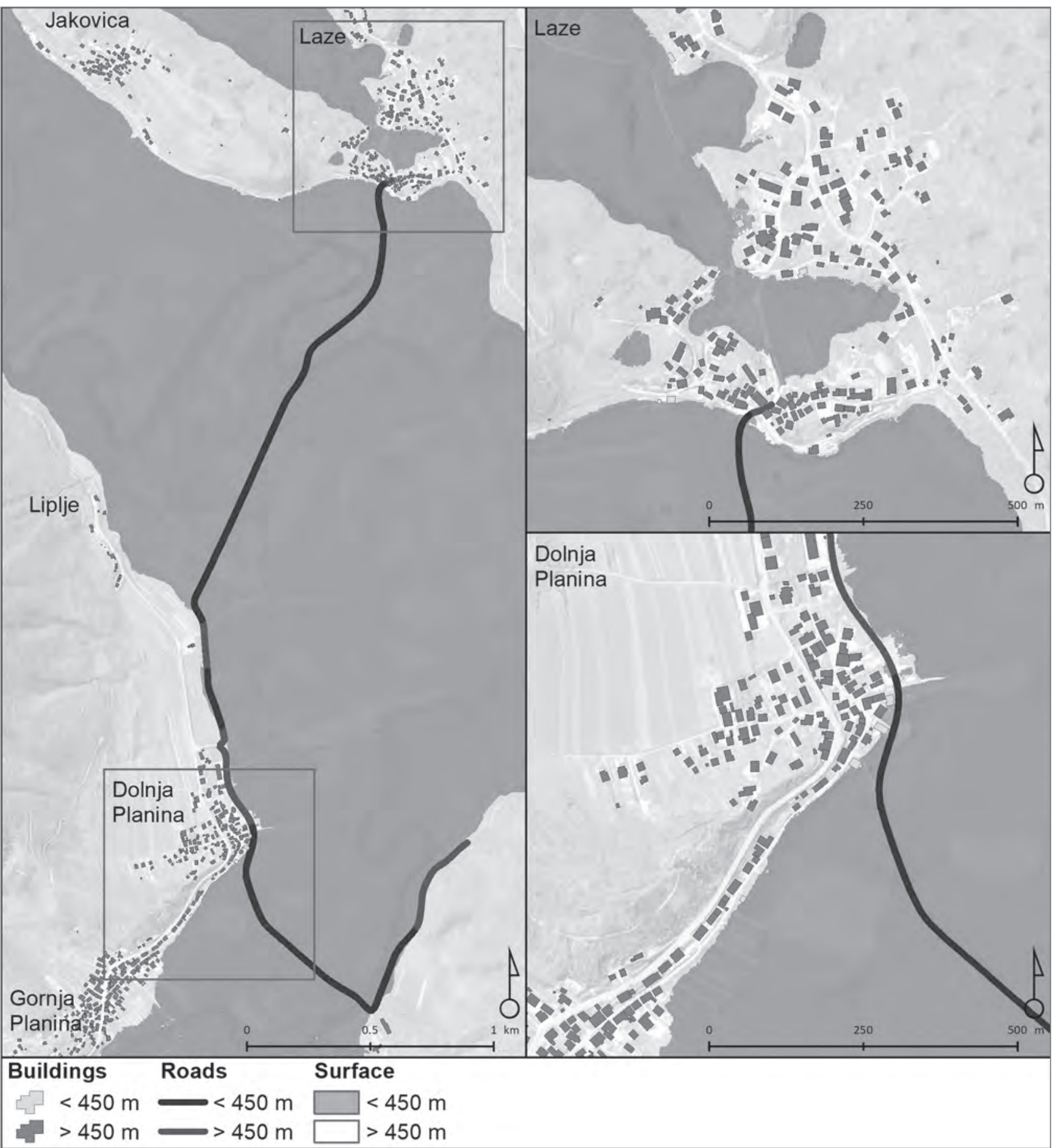

Figure 3: Water reaching 450 m (map by: Simon Koblar; source: Agencija Republike Slovenije za okolje, 2015 and Geodetska uprava Republike Slovenije, 2017, 2018).

from and attitudes toward flooding, and the human impact on floods. This provided the basis for developing a questionnaire for people in the study area.

\subsection{Defining research techniques}

After establishing the base for the module, data collection tools and the target group were addressed. Based on the four target issues, a questionnaire was developed with five parts:
1) general user information, 2) the usual daily routine in the Planina Karst Field when there is no flooding, 3) threats from and attitudes toward flooding, 4) the usual daily routine in the karst field when it is flooded, and 5) the human impact on floods. Each of the five parts had its own structure and focus. Parts 1,3 , and 5 were suitable for structured, semi-structured, and (in a few cases) open questions. Parts 2 and 4 were related to individuals' daily routines and therefore suitable for filling in tables and making maps. 


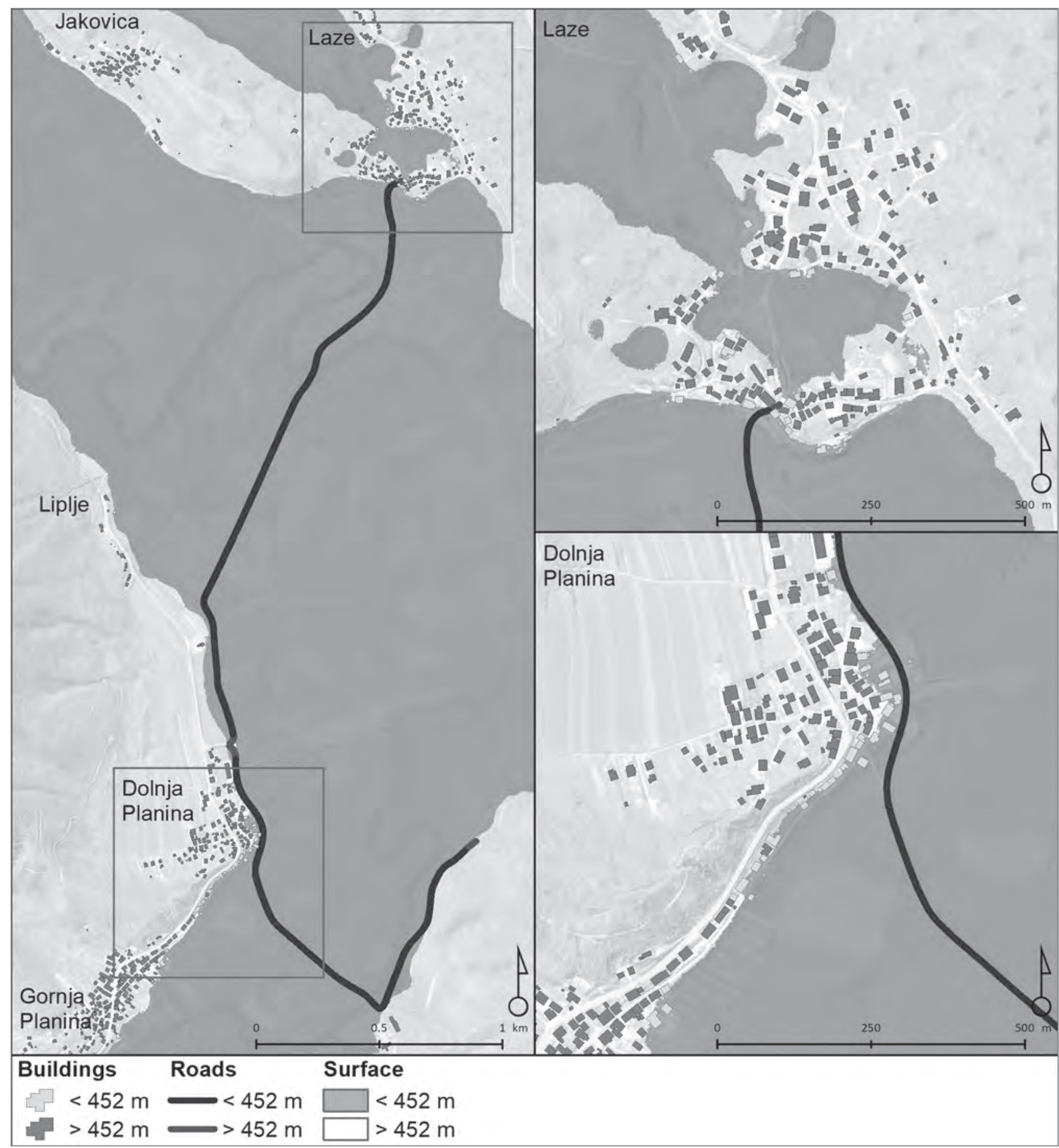

Figure 4: Water reaching 453 m (map by: Simon Koblar; source: Agencija Republike Slovenije za okolje, 2015 and Geodetska uprava Republike Slovenije, 2017, 2018).

Part 1 (general user information) was subdivided into eleven sections referring to basic descriptive data about the interviewees (year of birth, sex, activity, profession, education, place of residence, place of work, household size and characteristics, native vs. immigration status, and individual welfare level), all corresponding to the categories used by the Slovenian Statistical Office. Part 3 (threats from and attitudes toward flooding) starts with four open questions addressing flood threats, levels of threat regarding water level, ways flooding may threaten people in the karst field, and the influence of flooding on everyday life. The next set of questions addresses peoples' perception of flood causes and how floods influence their life and work, for both usual and extreme flood situations. The questions also address subjective experiences with extreme floods and flood damage. Finally, participants were also asked whether they would consider moving because of flooding. Like Part 3, Part 5 asked about some causal relations, focusing on the human impact on floods; that is, whether there is a rela- 


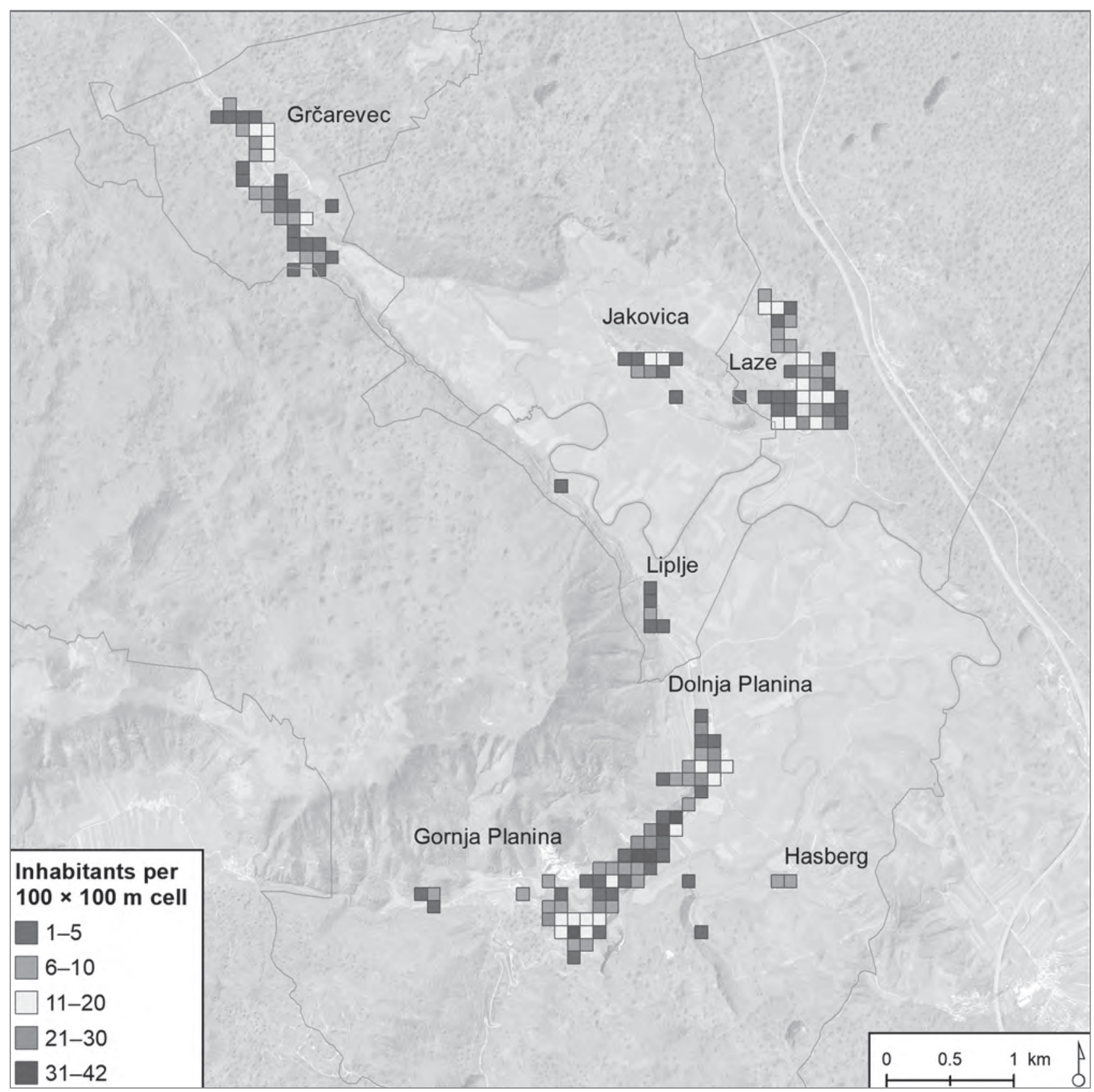

Figure 5: Number of people per settlement shown in a $100 \times 100 \mathrm{~m}$ grid (map by: Simon Koblar; source: Statistični urad Republike Slovenije, 2018b and Geodetska Uprava Republike Slovenije, 2017, 2018).

tion between people's activity in the karst field (residences, recreation, etc.) and flooding, and how can people influence flooding in the karst field.

Parts 2 and 4, dedicated to the people's daily routines when there is no flood (Part 2) or during a flood (Part 4), were composed of two pairs of sets of questions. The first part asked about a typical weekday routine, and the second about a typical weekend routine. In the case of no flood (Part 2), the questionnaire asked respondents to imagine a lovely day when it is nice to be outdoors. In addition to filling in a table describing activities people are involved with, the location where the activities take place, and the time of the activities, the respondents were also asked to enter the location of activities related to the karst field on a prepared map. A completed sample table and map were prepared as help. Options for administering the questionnaire were also considered. Several options were prepared: a face-to-face interview, an on-line questionnaire, and a combined approach. 


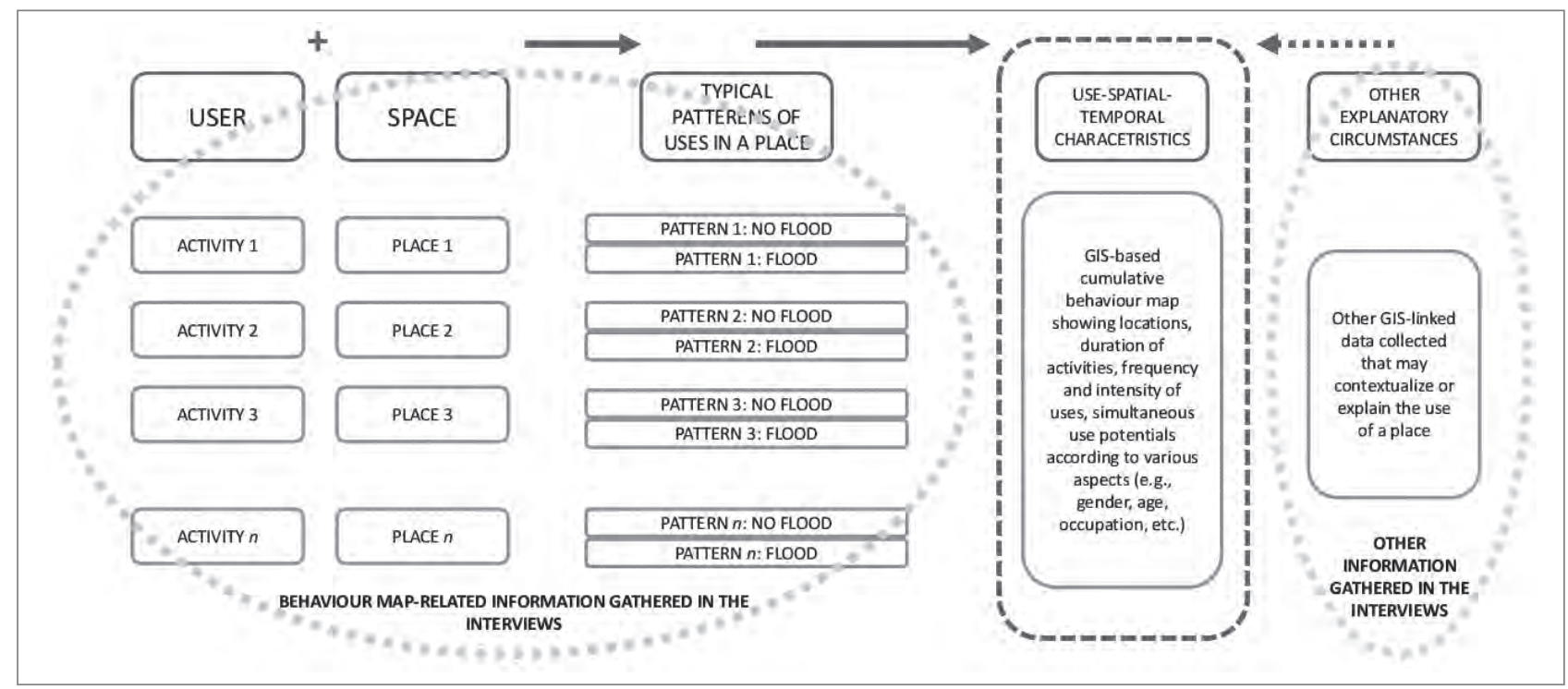

Figure 6: Components of the user-centred module and characteristics of daily routines (illustration: Barbara Goličnik Marušić).

\subsection{Methodology}

The protocol involved testing the interview method. For the testing phase, four individuals from the area were contacted based on a recommendation from the local authorities or local volunteers that contacted us after the project was presented in the local newspaper. The testing phase showed that the questionnaire fit the interviewees and confirmed the interview protocol. There was a strong preference for a face-to-face interview. However, in getting to know the area, its socio-economic structure (Statistični urad..., 2018a), and people's availability for collaboration, a specific user profile emerged as target group for building up and testing the module.

A second round of interviewee selection was based on recommendations from those previously interviewed and recommendations from the Karst Research Institute (a partner institution in the project mostly working on a hydro-geological module) or using random selection in order to meet the minimum criteria for the sample size. In the end, thirty-two participants were interviewed, sixteen women and sixteen men, average age fifty-six, half of them employed, and half of them already retired. The interviews followed the qualitative research concept and used a typical ethnographic research approach (e.g., Bernard, 2011). The interviews were conducted from 16 March to 9 September 2017. Each interview lasted one to two hours.

\section{A user-centred module}

The purpose of setting up a user-centred component in the conceptual model for an integral system of flood-sustainable planning is, first, to conceptualize a monitoring system for dynamic patterns of spatial use and users' daily routines and, second, to define user groups and thus acquire relevant input data corresponding to the characteristics of these user groups. The five-part questionnaire addressed both use and routine, and it included three main data sets: 1 ) users' activities, 2) locations where these activities took place, and 3) other circumstantial information (e.g., socioeconomic parameters of users' profile and attitudes about living in an area affected by floods). By overlapping the information about users' activities and the locations where they take place, new derived information emerges about typical patterns for how a place is used. This interprets two of the aspects of Hamilton et al.'s (2015) model: the human dimension (users' activities, characteristics, and circumstances) and the spatial scale (the dimension and accuracy of use). By adding the temporal dimension of the daily routine, it also addresses the time scale. By looking at patterns of use during floods and in non-flood conditions, it also interprets the temporal scale in a broader sense (considering the effects of seasons and weather) and also reflects on the natural setting. The final output combining these dimensions into the user-centred module is the temporal spatial-usage characteristic of the user profile. Figure 6 shows the components of the user-centred module and characteristics of the daily routines of the user profile examined.

\subsection{Data organization and coding}

A Microsoft Excel database was used to create a characteristic user profile from the interview sample. In addition to basic descriptive statistics, it also made possible various crosstab analyses of qualitative comments explaining the sample. The questionnaire data were entered into separate sheets based on the questionnaire ID. This database was then transformed into 
a GIS environment (ArcGIS 10.3.1), which made it possible to identify user-place relations and interactions.

A GIS database with relevant spatial data (e.g., terrain, orthophotos, land use, roads, buildings, and population data) was constructed. These base data made it possible to precisely digitalize user behaviour maps, which were presented with polylines. Those were combined with data from the questionnaire. This database allowed precise analysis and filtering of spatial data based on various criteria. GIS behaviour maps were produced from digitalized daily routines, which were reduced to activities outdoors and away from home. Thus, the analysis was oriented toward common or usual activities. These typical daily routines include recreational activities such as walking, hiking, or cycling as well as travel to work and for various services.

The data were collected in a verbal format describing the route used and time needed for the activity, and these data were transformed into a GIS-supported format. Each route had a duration variable. Because some interviewees were reluctant to estimate the time for an activity, the missing time data were calculated based on other clear cases (very clearly presented locations of routes and the time needed for traversing them).

To safeguard personal data, the collected routes were always calculated from the first closest intersection. All activities were coded. Walking as an activity was linked to routes located in the relatively flat area; hiking as an activity was linked to the routes leading into the surrounding hilly countryside. When an activity took place in the lower areas as well as in higher-lying countryside, it was marked with a combined code referring to walking and hiking. Cycling was also coded as a separate type of activity. Based on the reported times for routes taken for either activity, speed rates were calculated: walking $4.8 \mathrm{~km} / \mathrm{h}$, hiking (up and down) $2.6 \mathrm{~km} / \mathrm{h}$, repeated hiking up and down $3.4 \mathrm{~km} / \mathrm{h}$, moderate cycling $9.3 \mathrm{~km} / \mathrm{h}$, and faster cycling $19 \mathrm{~km} / \mathrm{h}$. Further, range was calculated with regard to time intervals. Activity duration units were rounded off at thirty- and sixty-minute intervals.

\subsection{Implementing and testing the module}

This section focuses on the concept of applicability and the principles applied, rather than on interpretation of the results themselves. It shows how such a module can contribute to an integrated model addressing flood issues in spatial planning.

\subsubsection{Analysing and interpreting the data collected}

First, the characteristics of user profiles were analysed to determine whether there were one or more user profiles in the area studied. To illustrate, a basic descriptive analysis of the collected data showed that the typical user profile was an elderly well-educated population ( $50 \%$ university degree, $41 \%$ high school degree) attached to the area (one-quarter of those interviewed work in their place of residence, one-quarter commute to other statistical regions, and retired persons are mostly at home). A high level of place attachment can also be interpreted from the fact that half of those in the sample are locals, and half of them moved there. Despite the flooding issues, all of them except for one person (due to age issues) would prefer to stay in the area. In terms of personal finances, the user profile indicates that the sample is comfortable (more than 60\% of the interviewees manage their daily expenses well, and 25\% consider themselves highly capable at managing daily expenses). Regarding affording hobbies and purchasing goods they are interested in, 25\% manage such needs well, 25\% consider themselves poor managers, and 50\% feel capable.

Second, the basic GIS-based analysis and its interpretation revealed characteristics of each routine. The results showed maps of locations and temporal dimensions: when and for how long each type of activity was performed and by whom (categorized by age group, sex, or use). To obtain the intensity of use (i.e., where, when, how long, and how often people tend to participate in an activity), advanced GIS-based analysis was carried out to produce composite behaviour maps. These refer to spatial-temporal ranges of use showing several spatial-temporal dimensions of place use. As an example, Figure 8 compares the intensity of using routes for walking and hiking during flooding and when the karst field is dry.

Such analysis makes it possible to comment on places' frequency and intensity of use. For planning or decision making, this can reveal potential carrying capacities of places in relation to changes (e.g., flooding or not). For example, in the test case it shows that when the karst field floods, recreation such as walking and/or hiking is not significantly affected. Instead, floods in the karst field attract people to enjoy the scenic landscape and to change their usual daily routines for walking in other areas not affected by the water. The influence of water is greater in the northern part of the karst field, where the routes between the meadows cannot be used and people more often use higher routes, usually roads. In the southwestern part, the area around Malenšcica Creek fills with water most quickly, and therefore the scenic routes between the Unica River and Malenšcica Creek and those through the wooded countryside toward Hasberg Castle cannot be used, and people choose either the road connecting the hamlet of Gornja Planina and Hasberg Castle, or more likely go for a walk in the higher-elevation woodlands. The analysis of the daily routine also showed that sometimes the cumulative time needed for walking is longer due to flooding in the karst field; in par- 


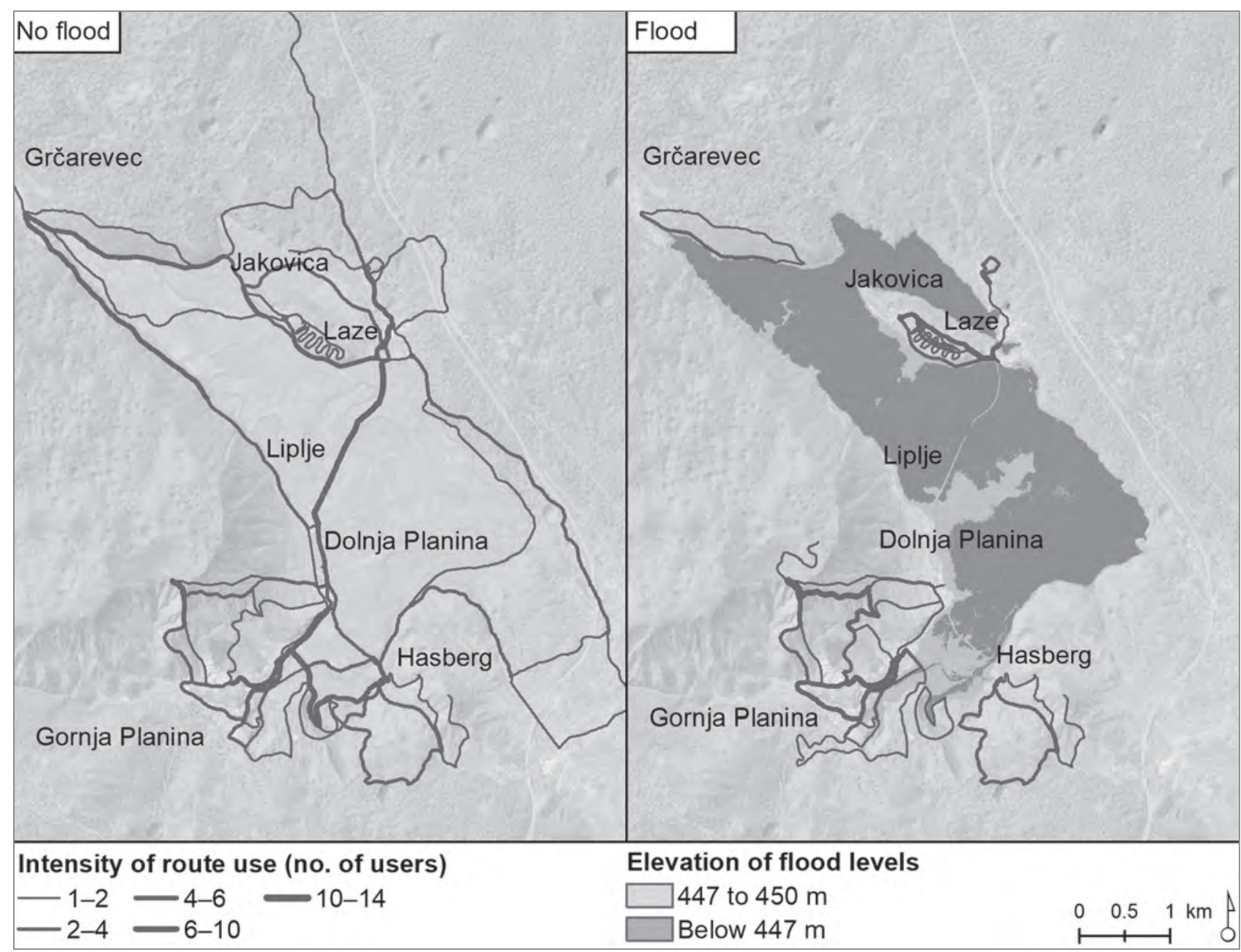

Figure 7: Comparison of intensity of using routes for walking and hiking during flooding and when the karst field is dry (map by: Simon Koblar; source: Geodetska uprava Republike Slovenije, 2017, 2018).

ticular, residents of Laze drive to the other side of the karst field (using the road from Laze to Ivanje Selo) to reach paths in the Hasberg Castle area. Interestingly, the paths between the fields in the bottom of the karst field leading to the river are not used for recreation, not even when the bottom of the karst field is dry.

However, there is a plan to provide visitors with a nature trail connecting various interesting parts of the karst field. Many parts of this planned trail cover routes that locals often use for recreation (in the southwest corner of the karst field), but it also includes a route toward the Unica River, which none of the sample uses as part of a daily routine. Even though this part of the planned trail remains dry during usual flooding, it has not been a popular daily recreation route. The rest of the proposed nature trail would usually not be accessible during flooding, but it is often used for recreation by locals. Empirical knowledge gained through a user-centred module may help in re-examining any existing or planned routes.
With these sets of small and qualitative data oriented toward users, space, and time, advanced GIS analysis makes it possible to study various temporal settings and also to comment on the usability of a place from a time-scale perspective. For example, in the case at hand, the frequency of route use is highest in the afternoon regardless of whether it is a weekday or weekend. During the week, this usage interval is slightly later, between $3.30 \mathrm{pm}$ and $6.00 \mathrm{pm}$, whereas on the weekend people go out after lunch, between $1.00 \mathrm{pm}$ and $3.30 \mathrm{pm}$. Thus, for example, behaviour maps originating from the user-centred module can show which routes are in use and how intensively during any particular section of the day.

Finally, the module makes it possible to study user profile characteristics in relation to engagement with places of interest; that is, it is possible to determine locals' recreational habits in the flooded karst field as well as when the karst field is dry. For example, people engage in recreation in their local area, and they may stay for a short time (thirty minutes) or go for 


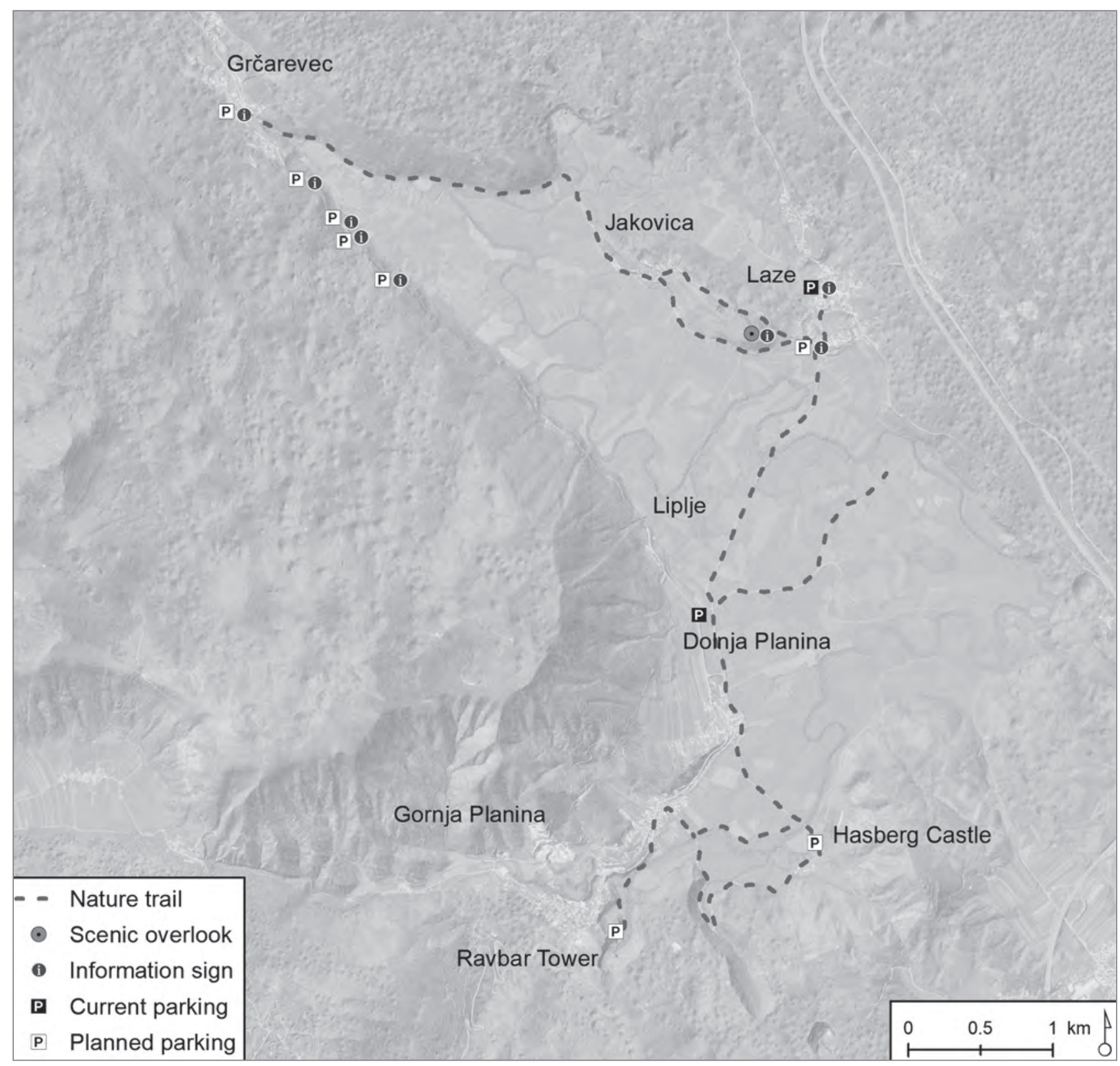

Figure 8: Plan for a nature trail in the Planina Karst Field (author: Simon Koblar; source: Notranjski regijski park, 2018).

a longer walk or hike (up to three hours), which means that in their local area they may walk from 1 to $10 \mathrm{~km}$. Comparative analyses of daily routines as an analytical tool may show how people modify their recreational walking during flooding; for the planning process, the daily routine approach can help address spatial capacity and may be useful as a valorization tool for decision-making. For this particular case, the user-centred module showed that flooding has no influence on walking or other recreational routines for only two of nineteen people that hike or walk for recreation.

While setting up the module, considerable attention was paid to parts of the questionnaire designed to acquire explanatory data, including data on levels of threats and damage connected with floods, experience with and attitudes toward floods, and causal relations between human activity and water dynamics as understood by the respondents (Sections 3 and 5). What emerged from this indigenous or place-based knowledge acquisition exercise is, first, information about a range of different situations occurring in a relatively small space. Furthermore, the hypothesis could be confirmed that people living in areas exposed to frequent flooding take this as an inherent feature of their living environment and include floods as a normal event in their everyday life and routines. In addition, a wealth of information could be obtained; for example, on former and current uses of the area, and on how individuals and the community have spontaneously adapted to flooding. Given the structure of the group interviewed, it did not seem relevant to 


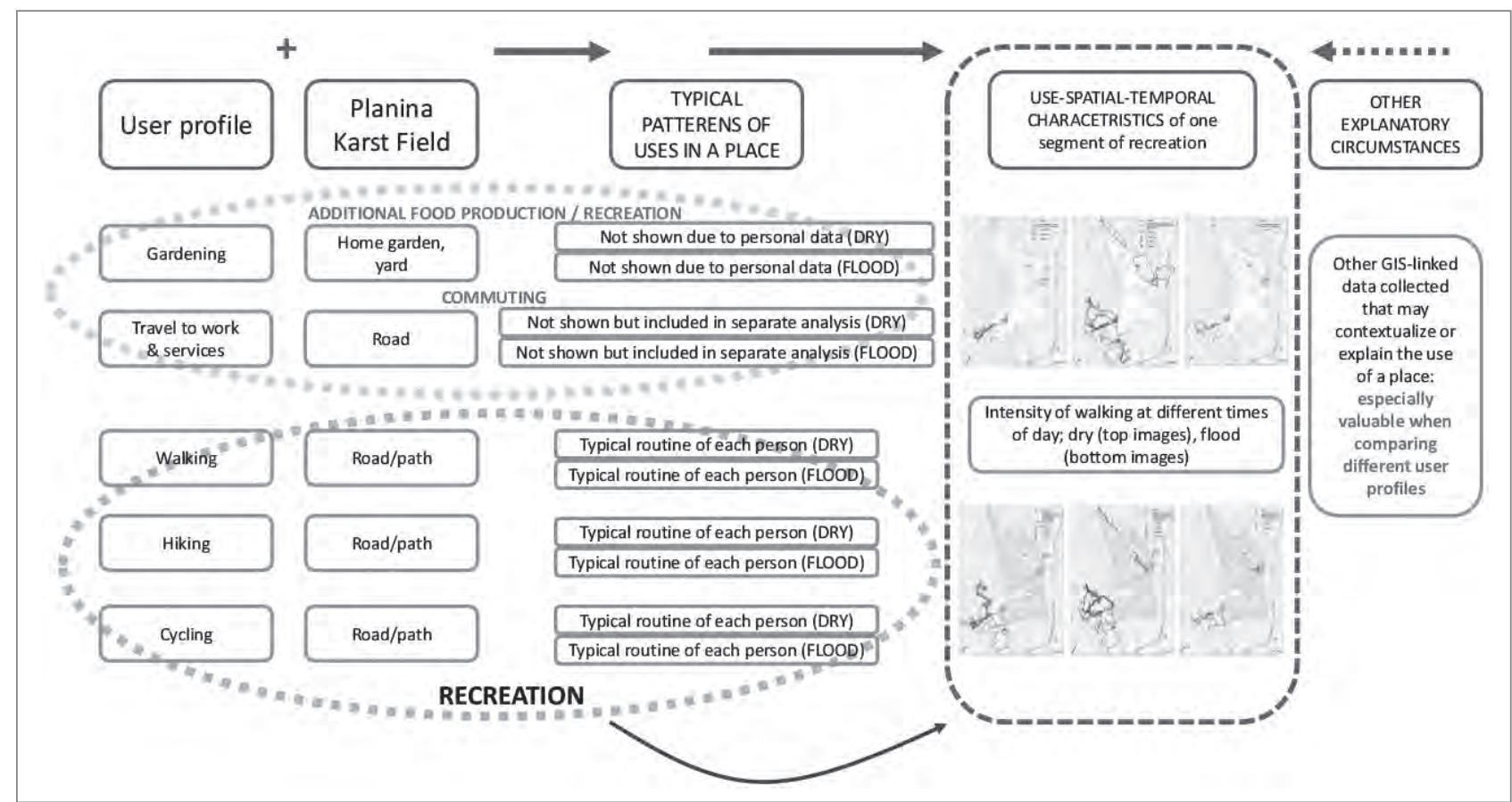

Figure 9: Steps taken in gathering and interpreting data for spatial-temporal representation of daily routines (illustration: Barbara Goličnik Marušić).

try to connect the results with specific user groups, but instead to treat them as general input for studying relations between people and a natural setting.

\subsubsection{Valorization of the module as a spatial planning analysis and interpretation tool}

The module follows a clear concept, in which the spatial-temporal dimensions of human residence are followed. It is built on the premise that such information is crucial for responsible and sustainable planning, exemplified by addressing flood-related issues. The user-centred module allows the acquisition of detailed (small, soft, and qualitative), content-related, and process-related data in a bottom-up manner. It follows a protocol including implementation methods and techniques, and it allows repetitive steps in any location of interest.

When applying the module, the capacity of spatial-temporal behaviour data (data related to daily routines gathered in questionnaire sections 2 and 4) had to be exploited first, and then cross-referenced with the package of explanatory data (questionnaire sections 1,3 , and 5). The steps taken to obtain the temporal spatial-use characteristics of the user-profile are shown in Figure 9.

Specific data gathered for a particular location have potential applicability for various steps at the local planning level. This article shows applicability for analytical phases or expert studies. However, the data may also be useful at a strategic level to form specific goals or as input for scenario building. By analysing temporal frameworks and spatial-use characteristics, it is possible to explore when, for how long, and with which intensity parts of an area are used and to speculate about various simultaneous uses of such a place. Thus, the module can address multifunctional landscapes. It can be used as a tool for identifying them or for assessing their potential (from a social point of view). In addition to its applicability potential in planning (e.g., in analysis, setting goals and visions, or developing strategies), the module concept can be a valuable tool for monitoring and analysis (i.e., comparing changes in usage dynamics before and after interventions). Indirectly, data gained in this manner can also be used at other planning levels, including regional or national. When original data collected bottom-up are properly generalized, they may serve as a basis for larger-scale planning and place local issues into a broader (spatial) context. Because daily routines are a central focus of the user-centred module, its concept may have a direct potential for mobility planning studies and implementation.

\section{Conclusion}

This article addresses the necessity of understanding, recognizing, and including the human dimension in a place as a relevant dynamic system in (flood-sustainable) spatial planning. The user-centred module introduces people's daily routines as relevant data for studying a dynamic system in a place where a process may influence or react to a natural dynamic system. 
The approach does not promote the public participation concept as such, but instead the inclusion of rather small, soft, and qualitative data in the planning process to obtain as much insight as possible into interactions between the natural and human systems, which may help in managing or planning areas. It demonstrates the potential for generalizing this method based on bottom-up data collection. Finally, spatial planning processes and activities can provide useful solutions for real life. The proposed approach addressing relations in time and space at an analytical level proceeds from a real-life scale, and it therefore informs the planning process with actual relations and keeps the entire process well-grounded with the actual places and their (non)spatial characteristics. In addition to various concepts of public participation, concepts such as the user-centred module, which implement and represent peoples' notions about spatial phenomena as well as temporal-spatial dimensions of their activities in places, offer new opportunities and challenges for a different view on spatial planning practice in the future.

Barbara Goličnik Marušić, Urban planning institute of the Republic of Slovenia, Ljubljana, Slovenia

E-mail: barbara.golicnik-marusic@uirs.si

Sergeja Praper Gulič, Urban planning institute of the Republic of Slovenia, Ljubljana, Slovenia

E-mail: sergeja.praper@uirs.si

\section{Acknowledgement}

This research was conducted as part of the projects J5-7178 Integral System of Flood-Sustainable Spatial Planning and J6-8266 Environmental Effects and Karst Water Sources: Impacts, Vulnerability and Adaptation of Land Use, which were financially supported by the Slovenian Research Agency. Special thanks to Ana Plavčak for fieldwork and related activities, and to Simon Koblar for support in GIS analysis and cartography.

\section{References}

Agencija Republike Slovenije za okolje (2015) Lidar. Available at: http:// gis.arso.gov.si/evode/profile.aspx?id=atlas_voda_Lidar@Arso (accessed 7 June 2018)

Bernard, H. R. (2011) Research methods in anthropology: Qualitative and quantitative approaches, fifth edition. London, Rowan \& Littlefield.

Cohen-Shacham, E., Walters, G., Janzen, C. \& Maginnis, S. (eds.) (2016) Nature-based solutions to address global societal challenges. Gland, IUCN. DOI: 10.2305/IUCN.CH.2016.13.en

Geodetska uprava Republike Slovenije (2017) E-geodetski podatki. Available at: https://egp.gu.gov.si/egp/ (accessed 7 June 2018).

Geodetska uprava Republike Slovenije (2018) Zbirka podatkov daljinskega zaznavanja - javna spletna storitev WMS. Available at: http:// prostor4.gov.si/imps/srv/slv/catalog.search\#/metadata/6ed30e0c-a49e-4 8bc-bc92-b7eeac1247fb (accessed 7 June 2018).
Goličnik Marušić, B. \& Marušić, D. (2012) Behavioural maps and GIS in place evaluation and design. In: Alam, B. M. (ed.) Application of geographic information systems, pp. 113-138. Rijeka, InTech.

Golledge, R. G. \& Stimson, R. J. (1997) Spatial behaviour: A geographic perspective. New York, The Guilford Press.

Hamilton, S. H., El Sawah, S., Guillaume, J. H. A., Jakeman, A. \& Pierce, A. (2015) Integrated assessment and modelling: Overview and synthesis of salient dimensions. Environmental Modelling \& Software, 64, pp. 215-229. DOI: 10.1016/j.envsoft.2014.12.005

IUCN (2012) The IUCN Programme 2013 - 2016. Available at: https:// cmsdata.iucn.org/downloads/iucn_programme_2013_2016.pdf (accessed 20 Nov. 2018).

Jiang, B. \& Xiaobai, Y. (eds.) (2010) Geospatial Analysis and Modelling of Urban Structure and Dynamics. Heidelberg, Springer.

Kovačič, G. \& Viršek Ravbar, N. (2010) Extreme hydrological events in karst areas of Slovenia, the case of the Unica River basin. Geodinamica Acta, 23(1-3), pp. 89-100. DOI: 10.3166/ga.23.89-100

Kragt, M. E., Newham, L. T. H., Bennett, J. \& Jakemann, J. A. (2011) An integrated approach to linking economic valuation and catchment modelling. Environmental Modelling \& Software, 26(1), pp. 92-102. DOI: 10.1016/j.envsoft.2010.04.002

Laniak, G. F., Olchin, G., Goodal, J., Voinov, A., Hill, M., Glynnm P., et al. (2013) Integrated environmental modelling: A vision and roadmap for the future. Environmental Modelling \& Software, 39, pp. 3-23. DOI: 10.1016/j.envsoft.2012.09.006

Marušić, D. \& Goličnik Marušić, B. (2016) Practical value of user-centred spatial statistics for responsive urban planning. In: Hung, M. C. (ed.) Applications of spatial statistics: Earth and planetary sciences, pp. 127-146. Rijeka, InTech. DOI: 10.5772/65322

Marušić, D. \& Goličnik Marušić, B. (2017) Time quality-measure for quality of place. In: Certoma, C., Dyer, M., Pocatilu, L. \& Rizzi, F. (eds.) Citizen empowerment and innovation in the data-rich city, pp. 125-142. Basel, Springer.

Marušič, J. \& Jančič, M. (1998) Regionalna razdelitev krajinskih tipov v Sloveniji - 4. Kraške krajine notranje Slovenije. Ljubljana, Ministrstvo za okolje in prostor Republike Slovenije.

MEA (2005) Millennium ecosystem assessment - Ecosystems and human well-being, volume 5. Washington, DC, Island Press.

Medema, W., Mclntosh, B. S. \& Jeffrey, P. J. (2008) From premise to practice: a critical asssment of integrated water resources management and adaptive management approaches in the water sector. Ecology and Society, 13(2), p. 29. DOI: 10.5751/ES-02611-130229

Müller, B., Bohn, F., Dreßler, G., Groeneveld, J. Klassert, C., Martin, R., et al. (2013) Describing human decisions and agent-based models $-\mathrm{ODD}+\mathrm{D}$, an extension of the ODD protocol. Environmental Modelling \& Software, 48, pp. 37-48. DOI: 10.1016/j.envsoft.2013.06.003

Naravovarstveni atlas (2018) Available at: https://www.naravovarstveni-atlas.si/web/ (accessed 7 June 2018).

Nesshöver, C., Assmuth, T., Irvine, K. N., Rusch, G. M., Waylen, K. A., Delbaere, B., et al. (2017) The science, policy and practice of nature-based solutions: An interdisciplinary perspective. Science of the Total Environment, 579, pp. 1215-1227. DOI: 10.1016/j.scititenv.2016.11.106

Notranjski regijski park (2018) Za obiskovalce. Available at: http:// www.kras.notranjski-park.si/planinsko-polje/za-obiskovalce/ (accessed 7 June 2018). 
Rebernik, N., Goličnik Marušić, B., Bahilo, A. \& Osaba, E. (in press) A 4-dimensional model and combined methodological approach to inclusive urban planning and design for all. Sustainable Cities and Society, 44, pp. 195-214. DOI: 10.1016/j.scs.2018.10.001

Statistični urad Republike Slovenije (2018a) Podatkovni portal SI-STAT. Available at: https://pxweb.stat.si/pxweb/dialog/statfile2.asp (accessed 20 Nov. 2018)

Statistični urad Republike Slovenije (2018b) Stage. Available at: http:// gis.stat.si/index.php (accessed 20 Nov. 2018).

UN (2015) The Sustainable Development Agenda. Available at: https:// www.un.org/sustainabledevelopment/development-agenda/ (accessed 20 Nov. 2018)

UNEP (2010) Report on the third ad hoc intergovernmental and multi-stakeholder meeting on an intergovernmental science-policy platform on biodiversity and ecosystem services - UNEP/IPBES. Nairobi, UNEP. Available at: https://www.ipbes.net/system/tdf/downloads/UNEP_IPBES_3_3_ EN.pdf?file=1\&type=node\&id=14239 (accessed 20 Nov. 2018).

UNEP/CBD (2000) Ecosystem Approach. Decisions adopted by the Conference of the Parties to the Convention on Biological Diversity as its Fifth Meeting, Nairobi, 15-26 May 2000. Available at: https://www.cbd.int/doc/ decisions/COP-05-dec-en.pdf (accessed 20 Nov. 2018).

van Ittersum, M. K., Ewert, F., Heckelei, T., Wery, J., Alkan Olsson, J., Andersen, E., et al. (2008) Integrated assessment of agricultural systems A component-based framework for the European Union (SEAMLESS). Agricultural Systems 96, pp. 150-165. DOI: 10.1016/j.agsy.2007.07.009

Vespignani, A. (2012) Modelling dynamical processes in complex socio-technical systems. Nature Physics, 8, pp. 32-39.

DOI: $10.1038 /$ nphys 2160

Viršek Ravbar, N., Barbera, J. A., Petrič, M., Kogovšek, J. \& Andreo Navaro, B. (2012) The study of hydrodynamic behaviour of a complex karst system under low-flow conditions using natural and artificial tracers (the catchment of the Unica River, SW Slovenia). Environmental Earth Sciences, 65(8), pp. 2259-2272. DOI: 10.1007/s12665-012-1523-4

Young, O. R., Berkhout, F., Gallopin, G. C., Janssen, M. A., Ostrom, E. \& van der Leeuw, S. (2006) The globalization of socio-ecological systems: an agenda for scientific research. Global Environmental Change, 16(3), pp. 304-316. DOI: 10.1016/j.gloenvcha.2006.03.004 